\title{
Evaluation of Educational Media Covering Biochemistry Concepts
}

\author{
Lima, C.A. ${ }^{1 . ;}$; Ferreira, A.O. ${ }^{1} ;$ Pereira, A.V. ${ }^{1}$, Hornink, G.G. ${ }^{1}{ }^{1}$ \\ ${ }^{1}$ Dep de Bioquímica, ICB-Unifal-MG, MG, Brazil
}

\begin{abstract}
INTRODUCTION: With the increase of Information and Communications Technologies, it has developed many tools which can be used in the biochemistry teaching, such as websites, films, educational software, that enable the visualization of microscopic and submicroscopic processes which has a difficult understanding. The use of software can be an integrating part of the teaching learning process, in order to assist or to contribute for a better construction of knowledge. OBJECTIVES: Identify the educational media available for teaching biochemistry and to evaluate, qualitatively, these tools. MATERIAL AND METHODS: The educational media were selected through searchers on the web and they were evaluated by four evaluators, using a specific questionnaire. The form was made using quality parameters in the following areas: media technical quality; educational aspects; content and use; and the use in virtual environments. A scale from 1 to 5 , NA (not applicable) were used and yes or no for the binary questions. After, was made the averages and standard deviations by category and media. RESULTS AND DISCUSSIONS: Were selected and evaluated 40 educational medias, highlighting the following results in the media technical quality: ease of access, ease of installation and reliability, however, need to improve the interactivity of these media, as well as accessibility. On the educational aspects issue the highlights are for updated information and the way they enable the construction of knowledge. When referring to the content assessed, the item that stood out was the exemption of textual errors. The lowest values of the evaluation, overall, gave up the use in virtual environments, indicating the demand for better integration with these environments. CONCLUSION: Applications reviews expressed concern in its construction, with respect to general aspects of quality, however, still demand a greater concern about the interaction with the student, and better accessibility and incorporation into virtual environments.
\end{abstract}

Keywords: Teaching biochemistry, educational media, evaluating medias Acknowledgment: Fapemig 